\title{
A study on knowledge and practice of mothers of under-five children regarding management of diarrhoea in urban field practice area of MRMC, Kalaburagi, Karnataka, India
}

\author{
Kiran Kumar Rokkappanavar*, S. R. Nigudgi, Shreeshail Ghooli
}

Department of Community Medicine, Mahadevappa Rampure Medical College, Kalaburagi, Karnataka, India

Received: 15 January 2016

Revised: 08 February 2016

Accepted: 09 February 2016

\section{*Correspondence:}

Dr. Kiran Kumar Rokkappanavar,

E-mail: kiranwaynestate@gmail.com

Copyright: () the author(s), publisher and licensee Medip Academy. This is an open-access article distributed under the terms of the Creative Commons Attribution Non-Commercial License, which permits unrestricted non-commercial use, distribution, and reproduction in any medium, provided the original work is properly cited.

\begin{abstract}
Background: Diarrhoea continues to be a major cause of morbidity and mortality among under-five children. Accurate knowledge regarding signs and symptoms, spread, prevention and healthy practices like exclusive breast feeding, immunization, ORS, good sanitary conditions are essential to prevent morbidity and mortality. Study was conducted with an objective of assessing knowledge and practice of mothers of under-five children regarding management of diarrhoea.

Methods: A cross-sectional study was carried out from June to August 2015. House to house survey was conducted; a pre-structured and pre-tested questionnaire was administered to all the mothers of under-five children in the study area.

Results: A total of 204 mothers were covered. Nearly two thirds (62.74\%) mothers were literate and majority of them were in the age group of 21-25 years. More than half of participants lacked adequate knowledge regarding danger signs, spread and prevention. Poor dietary practices were prevalent among 50.49\% mothers. Only 50.49\% mothers practiced exclusive breast feeding. Nearly one fifth of the mothers practiced bottle feeding, among them only $26.82 \%$ practiced hygienic measures. Majority of mothers (55.88\%) dispose child's faeces in open air. Only $43.62 \%$ mothers demonstrated proper technique of hand washing. $86.27 \%$ participants knew about ORS, among them more than half had adequate knowledge regarding preparation and administration. Only $26.96 \%$ mothers dewormed their child regularly.

Conclusions: A strong association is found between educational status and appropriate practices regarding diarrhoea management $(\mathrm{p}<0.001)$. Hence health education should be used as a tool to promote knowledge and good practice and reduce morbidity \& mortality.
\end{abstract}

Keywords: Knowledge, Practice, Under-five children, Diarrhoea, ORS

\section{INTRODUCTION}

Under-five age group is one of the vulnerable age groups for developing the infectious diseases. Globally, diarrhoea is the second most common cause of morbidity and mortality among them, following acute respiratory infection, and is also an important cause of malnutrition. ${ }^{1}$
On an average, children below three years of age in developing countries like India, experience about three episodes of diarrhoea each year. ${ }^{1}$ According to an estimate, there were 760,000 deaths worldwide $^{2}$ and 212,000 deaths in India due to diarrhoea. ${ }^{3}$ Most of the mortalities and morbidities due to diarrhoea can be prevented by practicing primary preventive measures 
such as use of clean water, hand washing, good cooking practices, exclusive breast feeding, immunization, sanitary disposal of excreta, use of latrines and good sanitary and hygienic practices. ${ }^{4,8}$ Secondary preventive measures include early recognition of dehydration due to diarrhoea and prompt oral rehydration by ORT, increased $\&$ continued feeding of energy dense food in addition to breastfeeding, zinc therapy and the use of appropriate antibiotics for severe cases of diarrhoea. ${ }^{2,8}$ Timely and appropriate management of cases at household and in health services remains an important intervention for reducing mortality due to childhood diarrhoea. ${ }^{5}$ According to NFHS III (National Family Health Survey), only $43 \%$ children suffering from diarrhoea receive any kind of ORT or increased fluids. Even more disturbing is the fact that this proportion seems to have stagnated or declined in most states in the last decade. ${ }^{6}$

Oral rehydration is yet to achieve its full potential in preventing diarrhoea deaths due to many factors such as poor socio-economic status, lack of knowledge among care givers and failure to provide therapy when needed. ${ }^{9}$ Further, diarrhoea treatment practices are not evidence based, as shown by the widespread prescription of unnecessary drugs. ${ }^{10}$

With reference to the pivotal role mothers play in management of diarrhoea, a joint statement of WHO/UNICEF stressed the need 'to understand their present attitudes, perceptions and practices regarding diarrhoea'?

One of the prime goals of millennium development goals \& National health mission (India) is to accelerate efforts towards reduction of childhood mortality. Diarrhoea is one of the important contributors of under-five mortality and most of these deaths are clustered around summer and monsoon season. To address this issue effectively, ministry of health and family welfare, India in conjunction with UNICEF has initiated a nationwide campaign known as intensified diarrhoea control fortnight (IDCF), which is conducted from $28^{\text {th }}$ July to 8th August of every year from 2014 with the ultimate aim of 'zero child deaths due to childhood diarrhoea'. IDCF also aims to achieve improved coverage of essential lifesaving commodity of ORS, zinc dispersible tablets and practice of appropriate child feeding practices during diarrhoea.

Information on factors playing role in diarrhoeal disease management, preventive measures and control strategies need to be understood for better planning, organization and implementation of health services within the community.

In this context, the present study was undertaken to assess the knowledge and practice of mothers regarding management of diarrhoea and to give health education to mothers.

\section{METHODS}

We carried out a community based cross sectional study from June to August 2015. The study area (Rajapur) is urban field practice area of M. R. Medical College, Kalaburagi, Karnataka, India. The total population of our study area was 3,778 with an under-five population of 409. The survey team consisted of interns, a health worker and a post graduate resident. The research protocol was approved by the institutional ethical committee.

The study interviewed the mothers in their households whose youngest child is five years old and below. Mothers who were residents in the study area for less than an year were excluded from the study. Study subjects were contacted by visiting every house and a pre-structured and pre-tested questionnaire was administered to them. A total of 204 mothers were covered. The interviewees were informed about the purpose and nature of the study in local language and the verbal informed consent was obtained before interviewing each participant. Questions were standardized in the local language to ensure uniformity in data collection. Diarrhoea was defined as per World Health Organization (WHO) definition. The questionnaire contained sections on socio-demographic data, data on immunization status, questions on knowledge and practice of management of diarrhoea, followed by preventive measures. The questions were framed as multiple choice questions with opportunity to choose more than one option in some questions.

Data was analysed using appropriate statistical methods such as percentage, proportion and chi square test. PSS software - version 16.0 was used for the analysis.

\section{RESULTS}

\section{Demographic profile}

In our study, majority of mothers $(59.31 \%)$ belonged to nuclear family followed by three generation family. Majority (43.62\%) of them were in the age group of 21 25 years. Majority $(37.25 \%)$ of mothers were illiterates. Most $(43.62 \%)$ of the study subjects had a monthly per capita income in the range of 1001-2000 rupees (Table 1).

\section{Knowledge regarding diarrhoea}

Most of the mothers $(93.13 \%)$ provided right description for the diarrhoea as per WHO definition. Only $39.71 \%$ of the study participants identified at least one danger sign of diarrhoea. Rest of them had no knowledge about it. Regarding the knowledge about the cause of diarrhoea, only $0.5 \%$ of the mothers said, it is because of infections. Regarding the knowledge about mode of spread, only $41.17 \%$ mothers identified at least one correct answer among the correct options (consuming the contaminated 
water, eating contaminated food, handling food with unhygienic fingers). Regarding the knowledge about preventive measures, only $40.68 \%$ mothers identified at least one correct answer among the correct options (drink boiled and cooled water, stop open air defecation, maintain personal hygiene and maintain hygienic surroundings) (Figure 1).

Table 1: Baseline demographic characteristics of 204 mothers of under-five children.

\begin{tabular}{|ll|}
\hline Category & Frequency \\
\hline Type of family & \\
\hline Nuclear & $121(59.31 \%)$ \\
\hline Three generation & $62(30.39 \%)$ \\
\hline Joint & $21(10.29 \%)$ \\
\hline Age (years) & $26(12.74 \%)$ \\
\hline Up to 20 & $89(43.62 \%)$ \\
\hline $21-25$ & $63(30.88 \%)$ \\
\hline $26-30$ & $26(12.74 \%)$ \\
\hline$\geq 31$ & \\
\hline Education of mothers & $76(37.25 \%)$ \\
\hline Illiterate & $19(9.31 \%)$ \\
\hline Primary (1-5) & $28(13.72 \%)$ \\
\hline Middle (6-8) & $41(20.09 \%)$ \\
\hline Secondary (9-10) & $19(9.31 \%)$ \\
\hline Higher Secondary (11-12) & $21(10.29 \%)$ \\
\hline Diploma and Graduation & \\
\hline Per Capita Income & $30(14.70 \%)$ \\
\hline Up to 1000 & $89(43.62 \%)$ \\
\hline $1001-2000$ & $85(41.66 \%)$ \\
\hline 22001
\end{tabular}

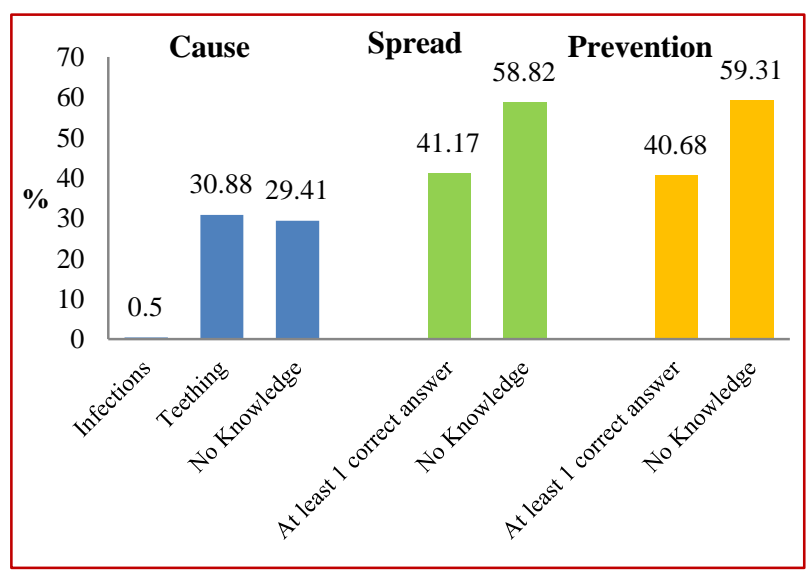

Figure 1: Distribution of mothers according to their knowledge about cause, spread and prevention of diarrhoea.

\section{Dietary practices}

$49.50 \%$ mothers were having adequate knowledge regarding diet to be followed during an episode of diarrhoea which is, continuation of breast feeding, and providing energy rich diet along with ORS. Majorities
$(50.49 \%)$ were of the opinion that, diet is to be restricted which is a wrong practice.

\section{Feeding practices}

Only $50.49 \%$ of the mothers practiced/practicing exclusive breast feeding at the time of the study. Remaining were either unaware or did not practice exclusive breast feeding. Among the study subjects, $20.09 \%$ practiced/practicing bottle feeding at the time of study. Further, for these mothers we asked questions to test the knowledge regarding method of keeping the hygiene of the bottle. Only $26.82 \%$ mothers practiced satisfactory techniques which included cleaning with hot water or soap. Rest of them practiced wrong techniques which included use of home based preparations for cleaning the bottle or using just the tap water (Figure 2).

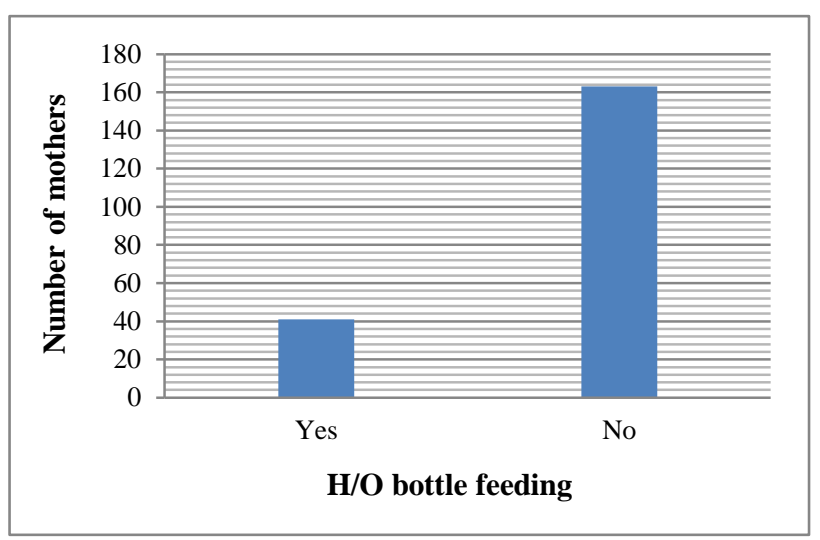

Figure 2: Distribution of mothers according to their practice of bottle feeding.

\section{Knowledge regarding $\mathrm{ORS}$}

Among the study subjects, majority (86.27\%) had knowledge about ORS sachets. When they were questioned regarding appropriate timing of administering ORS to the child, majority $(52.27 \%)$ of them gave correct answer i.e. ORS is to be administered during an episode of diarrhoea, whereas $46.02 \%$ mothers said they would give ORS to the child whenever child is sick. Majority of the mothers (58.52\%) had adequate knowledge regarding technique of preparing and using ORS solution. Only $22.15 \%$ of the mothers said they would taste the prepared ORS solution before giving it to the child.

\section{Treatment seeking behaviour}

Mothers were asked questions regarding the treatment they followed during the most recent episode of the diarrhoea. $28.92 \%$ mothers followed only household remedies which included herbal preparations. $33.82 \%$ mothers gave ORS to the child along with home remedy. 67 children $(32.84 \%)$ were taken to the hospitals and were given antibiotics. Among them, only 7 children received zinc supplements along with the medications. 


\section{Healthy practices}

Only $44.11 \%$ of mothers were using latrine rooms for disposing the child's faeces. Whereas $55.88 \%$ of mothers disposed child's faeces in open air. Though all the mothers said they would wash hands after disposing child's faeces, only $43.62 \%$ demonstrated proper technique of hand washing. Regarding personal hygiene, more than half $(51.47 \%)$ of mothers were not seen to be maintaining it. $26.96 \%$ mothers regularly dewormed their children using Albendazole tablet/syrup. Majority of the study subjects $(56.37 \%)$ used tap water directly for drinking purpose, whereas rest of them followed at least one of the recommended household methods of purifying drinking water. Regarding the method of storage of drinking water, majority $(70.58 \%)$ of them closed the lids whereas $29.41 \%$ kept the water container open and used directly for collecting water. Regarding immunization, $71.56 \%$ of the children have received age appropriate vaccine.

\section{DISCUSSION}

The study shows that mothers had a good understanding of diarrhoeal diseases $(93.13 \%$ of them) as per the description given by WHO. ${ }^{11}$ The proportion of mothers defining diarrhoea properly has been reported as $50 \%$ in studies from Rewa, Madhya Pradesh; 68\% in Wardha, Maharashtra; 35\% in Sudan; 65\% in Philippines and 79\% in Nepal. ${ }^{12-16}$ Mothers had limited knowledge regarding danger signs of diarrhoea. This finding is consistent with the reports from other studies conducted in India, Asia, Africa. ${ }^{14-16,19-21}$ Most of them were ignorant about the danger signs of diarrhoea.

A very few mothers had knowledge regarding the cause of diarrhoea. Only $0.5 \%$ of them gave correct answer i.e. infection as the cause of diarrhoea. In a study conducted in south east province of Iran, Khalili, et al reported $81 \%$ and 58\% mothers acknowledging unsafe water and unclean hands respectively as causes of diarrhoeal illness. ${ }^{17}$ Cabatbat, et al in their study conducted in Philippines reports $77 \%, 34 \%$ and $23 \%$ mothers acknowledging unsafe drinking water, failure to wash hands after defecating, and after handling faeces respectively as common reasons for diarrhoeal diseases. ${ }^{15}$ Surprisingly, in an Indian study conducted earlier, it had been reported just $15 \%$ and $6 \%$ mothers knowing that dirty water and dirty environment could cause diarrhoea. $^{12}$ In our study, nearly one third of the mothers were of the misconception that teething is the reason for development of diarrhoea. The magnitude of this misconception is also documented in other studies conducted in India as well as Iran, in these studies the magnitude is $64 \%$ and $48 \%$ respectively. ${ }^{12,17}$ Few of the mothers were also of the opinion that eating spicy food is the reason for development of diarrhoea in children. This is a cause of concern which needs to be rectified through health education.
Regarding the knowledge about spread of diarrhoea, many of them were of the opinion that contaminated water and food can be the reason, but more than half could not identify contaminated fingers also play an important role in the spread of infections. Focused health education of mothers in this regard may be of helpful as it is documented in earlier studies. ${ }^{25,26}$

Knowledge regarding the preventive measures is also inadequate among the mothers. More than half of them could not identify even a single measure from the options provided to them. To reinforce the earlier statement, focused health education of mothers in this regard may be of helpful. ${ }^{25,26}$

Knowledge regarding the diet to be followed during an episode of diarrhoea is also limited among the mothers. Nearly half of the participants said that diet needs to be restricted during the attack of diarrhoea which is a wrong answer. These observations are consistent with the observations made in research conducted by Suman, et al in Puducherry. ${ }^{27}$

Our study has noted another significant finding which is lack of awareness in population regarding importance of exclusive breast feeding as a tool in prevention of diarrhoea and its continuation during episodes of diarrhoea. Such low levels of awareness have been reported in a few other studies. ${ }^{15}$ Though a few percentages of mothers used (using) bottle feeding, majority of them used substandard home based preparation for cleaning the bottle. Such practices make the situation worse for contracting diarrhoea.

Though most of the women were aware of the ORS powder, only half of them knew the right way of using it. This proportion is higher compared to the data available from NFHS III in which it is $30 \% .^{18}$ Many of them answered that they would use the ORS solution whenever the child is sick, for whatsoever reason. This is a wrong practice and there is a need for behaviour change communication in this regard. WHO recommends tasting the ORS solution before giving it to the child. In our study only one fifth of the mothers followed this guideline.

Many of the mothers were able to take care of the episodes of diarrhoea by following household remedies along with ORS which is an appreciable practice. This practice is in contrast to the behaviour that mothers opting for medical consultations instead of initiation of home based ORT. Such consultations may lead to irrational prescription of antibiotics in children. ${ }^{22,23}$ This fact is more relevant when an estimate suggested about 150,000 under five diarrhoeal deaths in India are of Rotavirus origin. ${ }^{24}$ Only a few percentage of the children received zinc solution during an episode of diarrhoea. Most of those mothers who administered Zinc to their children had consulted medical doctors. The good part of consultation is most will receive zinc solution but 
practice of home based ORT needs to be promoted which helps in early reduction in dehydration even before the visit to the doctor.

\section{CONCLUSION}

Knowledge of mothers regarding danger signs of diarrhoea, cause, mode of spread and preventive measures is inadequate. Knowledge regarding technique of using ORS was unsatisfactory. Dietary practices among the mothers during the episode of diarrhoea are also unsatisfactory.

Wherever necessary, an attempt was made to fill the gaps in knowledge and practice of mothers. Soon after the mother completes the questionnaire, Health Education was given for those who did not practice Exclusive Breast Feeding; who could not maintain hygiene of feeding bottle. They were also educated regarding correct way and timing of using ORS; sanitary methods of disposing faeces; hand washing technique; household methods of purifying drinking water and vaccination.

In our study, a strong association was found between educational status of mothers and appropriate practices by them regarding diarrhoea management $(p<0.001)$. Hence health education should be used as a tool to promote knowledge \& good practice and reduce morbidity \& mortality.

\section{ACKNOWLEDGEMENTS}

Authors are thankful to Mr. AnilKumar Biradar (Health Inspector) for assisting us in house-to-house visit and data collection. We are thankful to interns for their help in filling proformas.

\section{Funding: No funding sources}

Conflict of interest: None declared

Ethical approval: The study was approved by the Institutional Ethics Committee

\section{REFERENCES}

1. The treatment of diarrhoea. A manual for physicians and other senior health workers. 4th rev. WHO. 2005:3.

2. WHO. Media Centre. Diarrhoeal disease. Fact sheet $\mathrm{N}^{\circ} \quad 330.2013 . \quad$ Available at: http://www.who.int/mediacentre/factsheets/fs330/en /. Accessed 25 August 2013.

3. Liu L, Johnson HL, Cousens S, Perin J, Scott S, Lawn JE. Global, regional, and national causes of child mortality: an updated systematic analysis for 2010 with time trends since 2000. Lancet 2012;379:2151-61.

4. Shah D, Choudhury P, Gupta P, Mathew JL, Gera T, Gogia S. Promoting appropriate management of diarrhoea: a systematic review of literature for advocacy and action. UNICEF-PHFI series on newborn and child health, India. Indian Pediatrics. 2012;49:627-49.

5. Jones G, Steketee RW, Black RE, Bhutta ZA, Morris SS. How many child deaths can we prevent this year? Lancet. 2003;362:65-71.

6. International Institute for Population Sciences (IIPS) and Macro International. National Family Health Survey (NFHS-3): 2005-06: India: Volume I. Mumbai: IIPS. Chapter 9, Child Health. 2007:23952.

7. The management of diarrhoea and use of oral rehydration therapy: A joint WHO/UNICEF statement. 2nd ed. WHO. 1985. Available at: http://hetv.org/pdf/management-ort.pdf. Accessed 16 August 2013.

8. Munos MK, Walker CL, Black RE. The effect of oral rehydration solution and recommended home fluids on diarrhoea mortality. International Journal of Epidemiology. 2010;39:i75-87.

9. Jha N, Singh R, Baral D. Knowledge, attitude and practices of mothers regarding home management of acute diarrhoea in Sunsari, Nepal. Nepal Med Coll J. 2006;8:27-30.

10. Wilson SE, Ouédraogo CT, Prince L, Ouédraogo A, Hess SY, Rouamba N. Caregiver recognition of childhood diarrhoea, care seeking behaviours and home treatment practices in rural Burkina Faso: a cross-sectional survey. PLoS One. 2012;7:e33273.

11. Diarrheal disease. WHO. Media Centre. Fact sheet N $\quad{ }^{\circ} 330 . \quad 2009 . \quad$ Available at:http//www.who.int.mediacentre/factsheets/fs330/ en/index/html. [Cited on 2013, August 14]

12. Kapoor P, Rajput VJ. Maternal knowledge, attitudes and practices in diarrhoea. Indian Pediatr. 1993;30:85-7.

13. Datta V, John R, Singh VP, Chaturvedi P. Maternal knowledge, attitude and practices towards diarrhoea and oral rehydration therapy in rural Maharashtra. Indian J Pediatr. 2001;68:1035-7.

14. Haroun HM, Mahfouz MS, Mukhtar ME, Salah A. Assessment of the effect of health education on mothers in Al Maki area, Gezira State, to improve homecare for children under five with diarrhoea. J Family Community Med. 2010;17:141-6.

15. Cabatbat AM. The effect of health education on the knowledge, attitudes and practices (KAP) on the mothers on diarrhoea in Barangay, Paglaun, Dumalinao, Zamboanga Del Sur. Zamboanga Medical School Foundation. 1999. Available at: http://som.adzu.edu.ph/research/pdf/2008-05-09100350 cabatbat.pdf. [Cited on 2013, August 16].

16. Ansari M, Ibrahim MIM, Shankar PR. A survey of mothers' knowledge about childhood diarrhoea and its management among a marginalized community of Morang, Nepal. AMJ .2011;4:474-9.

17. Khalili M, Mirshahi M, Zarghami A, Rajabnia MC, Farahmand F. Maternal knowledge and practice regarding childhood diarrhoea and diet in Zahedan, Iran. Health Scope. 2013;2(1):19-24. 
18. National Family and Health Survey, India. NFHS-3 (2005-2006). Available at: http://rchiips.org/nfhs/ NFHS-3\%20Data/VOL-1/Chapter\%2009\%20$\% 20$ Child $\% 20 \mathrm{Health} \%$ 20(562K).pdf. Accessed on March 1, 2016.

19. Jain SK, Khan JA. Epidemiological study of acute diarrheal disease and acute respiratory infection amongst under-five children in Alwar district (Rajasthan), India. Indian $\mathrm{J}$ Practicing Doctor. 2006;3(5). Available at: http://www.indmedica.com/journals.php?jo urnalid=3\&issueid $=91$ \&articleid $=1274 \&$ action $=$ arti cle. [Cited on 2013 August 14].

20. Saunders N. Maternal knowledge, attitudes, and practices concerning child health among mother of children younger than 60 months in Kep district, Kingdom of Cambodia. Final report. University of Toronto. Faculty of Medicine. Centre for International Health. 2005 Available at: http://wiki.straightjacketstudio.com/images/6/63/CI H2005-6-NSaunders- ChildHealthKAP.pdf. [Cited on 2013, August 16].

21. Rehan HS, Kunta G, Khargamaya G. Mothers needs to know more regarding management of childhood acute diarrhoea. Indian $\mathbf{J}$ PrevSoc Med. 2003;34(1,2):40-5.

22. Shah D, Choudhury P, Gupta P, Mathew JL, Gera T, Gogia S. Promoting appropriate management of diarrhoea: a systematic review of literature for advocacy and action. UNICEF-PHFI series on newborn and child health, India. Indian Pediatr 2012;49:627-49.

23. Kotwani A, Chaudhury RR, Holloway K. Antibiotic-prescribing practices of primary care prescribers for acute diarrhoea in New Delhi, India. Value Health. 2012;15(1):S116-9.

24. Tate JE, Chitambar S, Esposito DH, Sarkar R, Gladstone B, Ramani S. Disease and economic burden of rotavirus diarrhoea in India. Vaccine 2009;27(5):F18-24.

25. Pahwa S, Kumar GT, Toteja GS. Performance of a communitybased health and nutrition-education intervention in the management of diarrhoea in a slum of Delhi, India. J Health Popul Nutr. 2010;28:553-9.

26. Rishi RK, Bodakhe SH, Tailang M. Patterns of use of oral rehydration therapy in Srinagar (Garhwal), Uttaranchal, India. Trop Doct. 2003;33:143-5.

27. Saurabh S, Shidam UG, Sinnakirouchenan M, Subair M, Hou LG, Roy G. Knowledge and Practice Regarding Oral Rehydration Therapy for Acute Diarrhoea among Mothers of Under-Five Children in an Urban Area of Puducherry, India. Natl J Community Med. 2014;5(1):100-4.

Cite this article as: Rokkappanavar KK, Nigudgi SR, Ghooli S. A study on knowledge and practice of mothers of under-five children regarding management of diarrhoea in urban field practice area of MRMC, Kalaburagi, Karnataka, India . Int J Community Med Public Health 2016;3:705-10. 